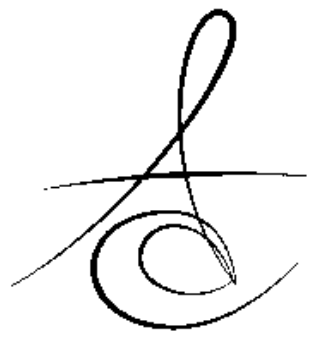

\title{
BÜYÜME VE GELİŞİMİ TAMAMLANMIŞ OLAN SINIF III BİR HASTANIN İSKELETSEL ANKRAJ KULLANARAK KAMUFLAJ TEDAVİSİ (OLGU SUNUMU)
}

\section{CAMOUFLAGE TREATMENT OF A NONGROWING CLASS III PATIENT BY USING SKELETAL ANCHORAGE (CASE REPORT)}

Araş Gör, Bilge Hamdiye CANTÜRK*

Doç. Dr. Mevlüt ÇELİKOĞLU**

Doç. Dr. Celal ÇANDIRLI***

Makale Kodu/Article code: 1425

Makale Gönderilme tarihi: 28.11.2013

Kabul Tarihi: 12.03.2014

\section{ÖZET}

$\mathrm{Bu}$ çalışmanın amacı iskeletsel Sınıf III malokluzyona sahip büyüme ve gelişimi tamamlanmış olan bir hastanın iskeletsel ankraj kullanılarak yapılan tedavi sonuçlarını sunmaktır.

15 yaşındaki bayan hasta alt dişlerinin protrüze olması şikayetiyle ortodontik tedavi için kliniğimize başvurmuştur. Hastanın klinik ve radyografik incelemeleri, hastanın dental ve iskeletsel Sınıf III ilişki ile birlikte düz bir profile sahip olduğunu göstermiştir. Hastanın düz bir profile, anteriorda baş başa keser ilişkisine sahip olmasından ve kendisinin kompansasyon tedavi seçeneğini tercih etmesinden dolayı Sınıf III elastiğin kullanımı için zigomatik buttress bölgesine yerleştirilen miniplakların kullanımı ile Sınıf III malokluzyonun tedavisine karar verilmiştir. Maksiller ve mandibular dişlerin seviyelenmesinden sonra 6 ay boyunca miniplaklar ile mandibular kanin dişler arasına intermaksiller Sınıf III elastik uygulanmıştır. 15 aylık toplam tedavi süresi sonunda Sınıf I molar ve kanin ilişki elde edilmiştir.

Büyüme ve gelişimi tamamlanmış olan bir hastanın ortodontik kamuflaj tedavisi, miniplak ankrajı ile kısa bir sürede başarılı bir şekilde yapılmıştır.

Anahtar Kelimeler: Sınıf III, İskeletsel ankraj, Kamuflaj tedavisi

\section{ABSTRACT}

The aim of the present study is to present skeletal and dental treatment outcomes of a nongrowing patient with skeletal Class III malocclusion treated using skeletal anchorage.

A 15 year-old female patient had applied to our clinic for orthodontic treatment with chief complaint of her lower teeth being protrusive. Clinic and radiographic examination of the patient showed that she had a straight profile with dental and skeletal Class III relationship. Since she had straight profile, edge to edge anterior tooth relationship and, chose compensation therapy choice, we decided to treat Class III malocclusion using miniplates inserted on zygomathic buttress for the use of Class III elastics. After leveling of maxillary and mandibular teeth, intermaxillary class III elastics between miniplates and lower canines were applied for 6 months. After 15 months of total treatment time, Class I canine and molar relationships were established.

Orthodontic camouflage treatment of a nongrowing patient was successfully performed in a short time with miniplate anchorage.

Key Words: Class III, Skeletal anchorage, Camouflage treatment

\section{GİRİş}

Sınıf III malokluzyonlar tedavisi en zor ve karmaşık olan malokluzyonlardan biridir. $^{1}$ İskeletsel Sınıf III malokluzyon, mandibular prognati, maksiller retrognati veya her ikisinden kaynaklı olabilir. ${ }^{2-4}$ Sınıf III malokluyonların tedavi seçenekleri, malokluzyonun meydana geldiği çeneye ve bireyin içinde bulunduğu büyüme dönemine göre farklılıklar göstermektedir. Büyüme ve gelişimi devam eden bireylerde ortopedik

*Karadeniz Teknik Üniversitesi, Diş Hekimliği Fakültesi, Ortodonti Ana Bilim Dalı,

**Akdeniz Üniversitesi, Diş Hekimliği Fakültesi, Ortodonti Ana Bilim Dalı,

***Karadeniz Teknik Üniversitesi, Diş Hekimliği Fakültesi, Ağız, Diş ve Çene Cerrahisi Ana Bilim Dalı, 
tedavi ile büyümenin yönlendirilmesi başı̆ıca tedavi yaklaşımıdır. ${ }^{5,6}$ Erişkin bireylerde ise hafif veya orta şiddette bir iskeletsel malokluzyonun ve kabul edilebilir bir fasiyal estetiğin mevcut olduğu durumlarda sabit mekanikler ile kamuflaj tedavisi tercih edilebilirken şiddetli iskeletsel uyumsuzluklarda tek tedavi seçeneği ortognatik cerrahi olmaktadır. ${ }^{7}$

Kamuflaj tedavisinin amacı, iskeletsel uyumsuzluğun dentoalveolar kompansasyonu (maksiller keserlerin proklinasyonu ve mandibular keserlerin retroklinasyonu) ile kabul edilebilir bir oklüzyon, fonksiyon ve estetik sağlanmasıdır. ${ }^{8-11}$ Ancak dentoalveolar kopmansasyon sırasında maksiller keser dişlerin proklinasyonu kaçınıımaz olmaktadır. ${ }^{12}$ Artmış maksiler kesici labial eğimi, gülümseme arkının düzleşmesine ve kesici görünümünün azalmasına neden olmaktadır. Bu durum fasiyal profilin statik ve dinamik güzelliğini fazlasıyla bozmakta ve aynı zamanda tedavinin stabilitesini de riske atmaktadır. ${ }^{13,14}$

Sinıf III malokluzyonun kamuflaj tedavisinde son yıllarda oldukça popüler olan iskeletsel ankraj mekaniklerinin kullanımı ile mandibular dentistyonun en-masse distalizasyonu maksiller keserlerin aşırı proklinasyonunu engellemek açısından oldukça etkili olmaktadır. ${ }^{12,14}$

Bu vaka raporunun amacl, iskeletsel Sinıf III malokluzyona sahip büyüme ve gelişimi tamamlanmış olan bir hastanın iskeletsel ankraj kullanılarak yapılan kamuflaj tedavisinin sonuçlarını sunmaktır.

\section{OLGU SUNUMU}

15 yaşındaki bayan hasta alt dişlerinin protrüze olması şikayetiyle ortodontik tedavi için kliniğimize başvurmuştur. Hastanın anamnezinde genel sağlık durumunun iyi olduğu ve ortodontik tedavi için herhangi bir kontrendikasyon olmadığı görülmüştür. Hastanın ailesinde ve yakın akrabalarında Sınıf III malokluzyon bulunmamaktadır.

Klinik incelemede hastanın düz bir profile, protrüziv bir alt dudağa, sağ ve sol tarafta Sinıf III molar ve kanin ilişkisine ve baş başa keser ilişkisine sahip olduğu saptanmıştır. Maksiller dental orta hat yüz orta hattı ile uyumluyken mandibular orta hat 2 $\mathrm{mm}$ sağa sapmıştır. Hayes Nance model analizinde üst çenede $1 \mathrm{~mm}$ yer intiyacl, alt çenede ise $2,5 \mathrm{~mm}$ yer fazlalığı tespit edilmiştir (Resim 1). Panoramik incelemede, hastanın tüm 20 yaş dişlerinin mevcut olduğu görülmüştür. El-bilek filminde kemik yaşı Greulich-Pyle atlasına göre 16 yıl olarak tespit edilmiştir (Resim 2). Bolton analizine göre mandibular anterior dişlerde $1 \mathrm{~mm}$ bolton fazlalığı mevcuttur. Sefalometrik incelemede hastanın mandibular prognati (SNB: $84,3^{\circ}$ ) kaynaklı iskeletsel Sınıf III malokluzyona (ANB: $-3,7^{\circ}$ ) sahip olduğu tespit edilmiştir. Hastanın dik yön boyutları normal sınırlar içerisindedir (SN/GoGn: $29^{\circ}$ ), üst keser dişleri protrüzedir (U1/SN: $\left.124,6^{\circ}\right)$. Üst dudak $S$ doğrusuna göre geride $(-1,6$ $\mathrm{mm})$, alt dudak ileride $(+1,6 \mathrm{~mm})$ konumlanmıştır (Tablo 1).

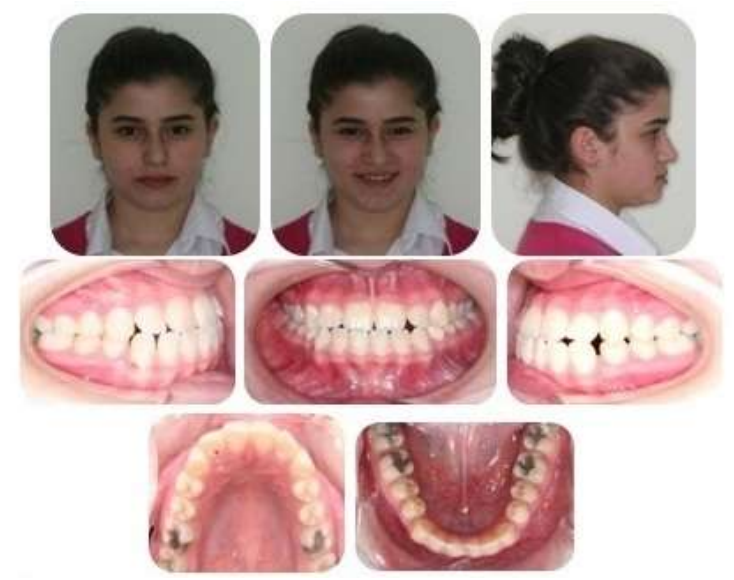

Resim 1. Hastanın başlangıç ağız dışı - ağız içi fotoğrafları

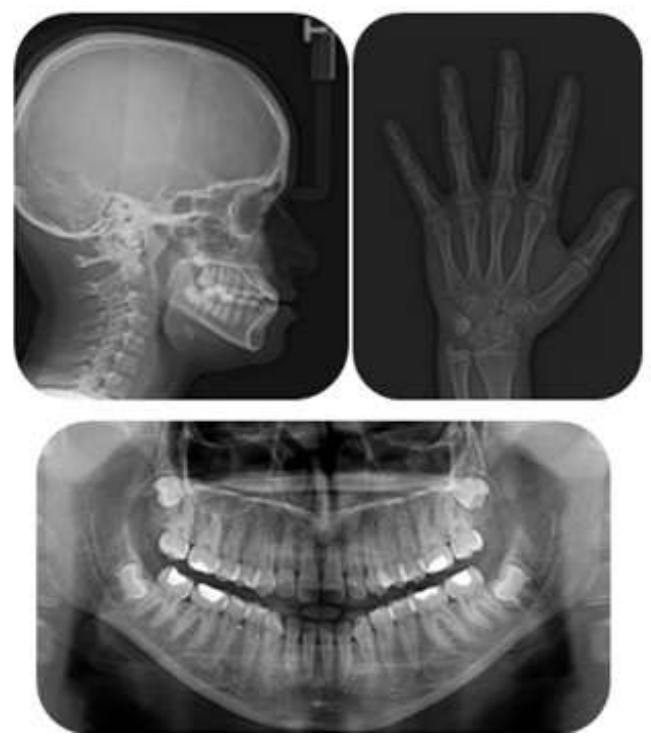

Resim 2. Hastanın başlangıç filmleri

Tablo 1. Hastanın tedavi öncesi ve sonrası sefalometrik 
ölçümleri.

\begin{tabular}{lll} 
Ölçümler & Başlangıc & Bitim \\
\hline SNA $\left(^{\circ}\right)$ & 80,4 & 80,5 \\
\hline SNB $\left(^{\circ}\right)$ & 84,1 & 84,3 \\
\hline ANB $\left(^{\circ}\right)$ & $-3,7$ & $-3,8$ \\
\hline SND $\left(^{\circ}\right)$ & 81,1 & 81,0 \\
\hline SN/OD $\left(^{\circ}\right)$ & 16,3 & 12,6 \\
\hline SN/GoGn $\left(^{\circ}\right)$ & 29,0 & 28,3 \\
\hline U1/SN $\left(^{\circ}\right)$ & 124,6 & 122,3 \\
\hline IMPA $\left(^{\circ}\right)$ & 91,2 & 80 \\
\hline Overjet $(\mathrm{mm})$ & 0 & 2 \\
\hline Overbite $(\mathrm{mm})$ & 0 & 2 \\
\hline Ls-S $(\mathrm{mm})$ & $-1,6$ & $-2,2$ \\
\hline Li-S $(\mathrm{mm})$ & 1,6 & $-0,6$ \\
\hline
\end{tabular}

Hastaya tedavi seçenekleri olarak ortognatik cerrahi ve çekimli/çekimsiz kamuflaj tedavisi sunulmuştur. Hastanın düz bir profile, baş başa keser ilişkisine sahip olmasından ve kamuflaj tedavi seçeneğini tercih etmesinden dolayı Sınıf III elastiğin kullanımı için zigomatik buttress bölgesine yerleştirilen miniplakların kullanımı ile Sınıf III malokluzyonun tedavisine karar verilmiştir.

\section{Tedavi planlamasında amaçlar;}

$\checkmark$ Üst ve alt arkın seviyelenmesi,

$\checkmark$ Üst keserleri daha fazla protrüze etmeden ideal bir

overjet ve overbite ilişkisinin sağlanması,

$\checkmark$ Mandibular orta hat sapmasının düzeltilmesi,

$\checkmark$ Sınıf I kanin ve molar ilişkinin elde edilmesidir.

Hastanın tedavisinde alt ve üst dişlere 0.022 slot braketler yerleştirilmiştir. Yuvarlak ve köşeli NiTi teller ile dişlerin sıralanması ve seviyelenmesi 6 ay sürmüştür. Seviyeleme işleminin tamamlanmasından sonra alt ve üst arka 0,019 x 0,025 çelik teller yerleştirilmiştir ve cinch back bükümü yapılmıştır. Ankraj olarak kullanılacak zigoma ankraj plakları (Multi Purpose Anchor MPI 1000, Tasarim Med, Istanbul, Turkey) lokal anestezi altında fakültemizin Ağız ve Çene Hastalıkları Cerrahi Anabilim Dalı' nda tecrübeli bir cerrah tarafından yerleştirilmiştir. Daha sonra mandibular arkın en-masse distalizasyonu için miniplaklar ile mandibular kanin dişler arasına bağlanan Sınıf III elastikler ile tek taraflı 300 gr kuvvet uygulanmıştır. Hastaya bu elastikleri 24 saat boyunca kullanması ve sadece yemeklerde çıkartması söylenmiştir. 6 ay süren distalizasyon işleminden sonra okluzal settling işlemine geçilmiştir. Toplam 15 aylık aktif tedavi süresi sonunda debonding işlemi yapılarak pekiştirme amacıyla üst çeneye essix plağı, alt çeneye kaninler arası lingual retainer ve essix uygulanmıştır.

Yapılan ortodontik kamuflaj tedavisi sonucunda orta hat sapması düzeltilmiş, üst keserleri daha fazla protrüze etmeden ideal bir overjet ve overbite ilişkisi sağlanmış ve Sınıf I kanin ve molar ilişki elde edilmiştir (Resim 3-4). Bununla birlikte klinik olarak başarılı bir sonuç alınmasına rağmen iskeletsel ölçümlerde önemli bir değişim meydana gelmemiştir (Şekil 1). Hastanın dik yön boyutlarında azalma (GoGn/SN: $-0,7^{\circ}$ ) olmuştur. Yumuşak doku değerlendirildiğinde ise alt dudağın kesici diş retraksiyonunu (IMPA: $-11,2^{\circ}$ ) takip ettiği ve $S$ doğrusuna göre ideal konuma geldiği görülmüştür (Li-S: $-0,6 \mathrm{~mm}$ ). Bu şekilde profilde memnun edici bir düzelme sağlanmıştır (Tablo 1).

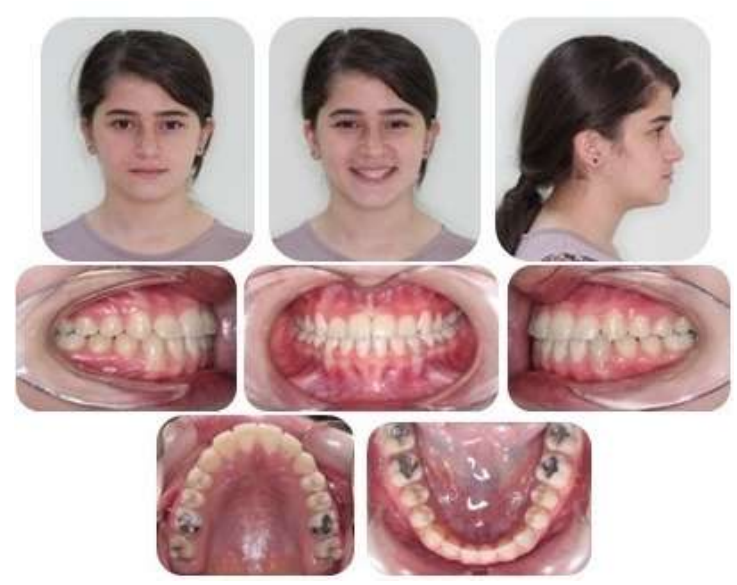

Resim 3. Hastanın bitim ağız dışı - ağız içi fotoğrafları

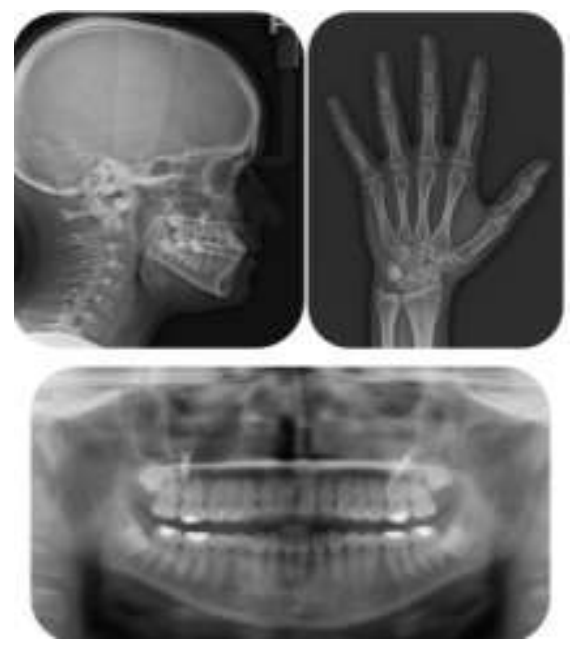

Resim 4. Hastanın bitim filmleri. 


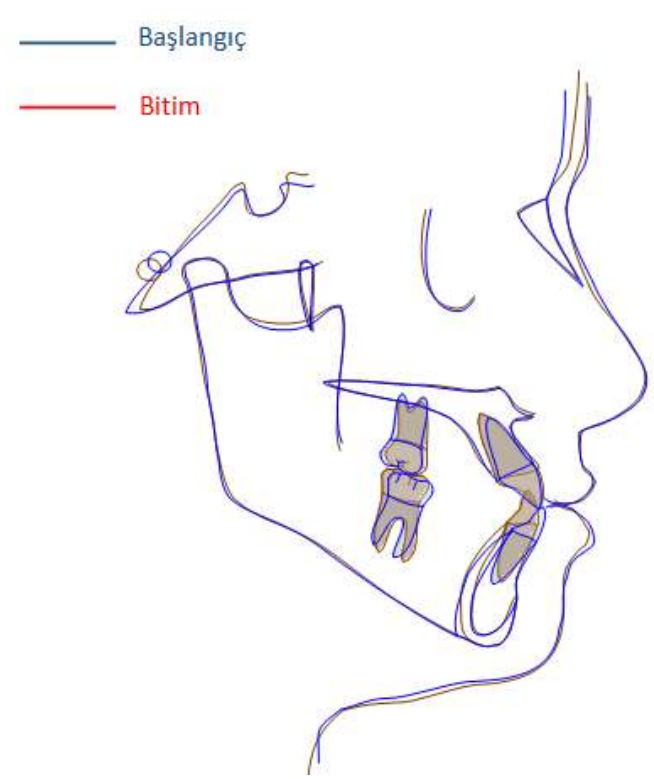

Şekil 1. Hastanın tedavi başı ve sonu total çakıştırması.

\section{TARTIŞMA}

Literatürde kamuflaj tedavisinin, hafif ve orta dereceli sagital yöndeki iskeletsel problemlerde hastanın dik yön boyutları artmamış, çapraşıklık miktarı az ve yumuşak doku profil görünümünün kabul edilebilir olduğu durumlarda yapılabileceği belirtilmiştir. ${ }^{15} \mathrm{Bu}$ vaka raporunda hastada yukarıda belirtilen şartlar mevcut olduğu, hasta cerrahi ve çekimli kamuflaj tedaviyi kabul etmediği için kendisinin ve ebeveynin onayı alınarak iskeletsel ankraj destekli çekimsiz kamuflaj tedavi yaklaşımı uygulanmıştır.

Retrognatik bir maksilla veya prognatik bir mandibuladan kaynaklanan Sınıf III malokluzyona sahip hastalarda maksiller keserlerin proklinasyonu ve mandibular keserlerin retroklinasyonu ile dentoalveolar kompansasyonlar meydana gelmektedir.,16 Ayrıca Sınıf III malokluzyonun kamuflaj tedavisinde kullanılan intermaksiller elastikler ile maksiller keserlerin proklinasyonu da kaçınılmaz olmaktadır. Bu şekilde ortaya çıkan maksiller keserlerin aşırı labioversiyonu gülümsemeyi olumsuz yönde etkilemektedir. ${ }^{12,13} \mathrm{Bu}$ nedenle bu vakada keser protrüzyonuna sebep olmayacağı düşünülen miniplak ankrajı ile mandibular dentisyonun distalizasyonu tercih edilmiştir.

Literatürde iskeletsel ankraj mekaniklerinin kullanımı ile mandibular dentisyonun en-masse distalizasyonun başarılı bir şekilde yapıldığı bildirilmektedir. Jink ve $\mathrm{ark}^{12}$, orta dereceli protrüziv bir mandibula ve anterior çapraz kapanış ile birlikte iskeletsel Sınıf III malokluzyona sahip 20 yaşında bir hastanın kamuflaj tedavisinde ramusun eksternal oblik bölgesine bilateral olarak yerleştirilen mini vidalardan kanin ve birinci premolar dişler arasındaki çengele uzanan koil springlerle 300 gram kuvvet uygulamışlardır ve 12 ayda mandibular dentisyonun en-masse distalizasyonu (keserler ve molarlar yaklaşık $4 \mathrm{~mm}$ ) gerçekleştirilmiştir. Suguwara ve ark ${ }^{17}$, Sınıf III maloklüzyona ve anterior çapraz kapanışa sahip 50 yaşındaki bir bayan hastada retromolar bölgeye yerleştirdikleri mini vidalardan ikinci premolar ve birinci molar dişler arasındaki çengele koil springler ile $100 \mathrm{gr}$ kuvvet uygulayarak mandibular dentisyonu distalize etmişlerdir ve bu şekilde tedavinin sonunda kabul edilebilir bir oklüzyon elde edilmiştir. Ancak mandibulada minivida kullanımının başarısızlık oranının yüksek ve miniplaklara göre stabilite kaybının fazla olduğu literatürde belirtilmektedir. ${ }^{18,19} \mathrm{Bu}$ nedenle bu vakada iskeletsel ankraj olarak mini vida yerine miniplak kullanımı tercih edilmiştir.

Hastanın tedavisinde miniplak destekli Sınıf III elastiklerin kullanımı ile mandibular dentisyonun distal hareketi ve okluzal düzlemin saat yönünün tersine rotasyonu meydana gelmiştir. Mandibular dentisyonun distalizasyonu sırasında uygulanan Sınıf III elastiğin üst dentisyonun yerine zigomatik buttress bölgesine yerleştirilen miniplaklardan ankraj alması sonucu maksiller keser dişlerde daha fazla proklinasyon meydana gelmemiştir. Miniplaklardan mandibular kanin dişlere uygulanan Sınıf III elastiklerin kuvvet yönünün mandibular arkın direnç merkezinin üzerinden uygulanması nedeniyle mandibula saat tersi yönünde rotasyon yapmıştır ve okluzal düzlem düzleşmiştir. Buna bağlı olarak hastanın dik yön boyutlarında hafif bir azalma (GoGn/SN: $-0,7^{\circ}$ ) ve overbite ölçümünde (+2 mm) artış meydana gelmiştir. Tedavi ile alt kesici dişlerde meydana gelen retrüzyon tedavi öncesinde belirgin olan alt dudağın ideal konuma yaklaşmasını sağlamıştır ve bu da profilde memnun edici bir düzelmeye neden olmuştur. Hastada ideal overjet ve overbite ilişkisi elde edildiği ve hastanın büyümesi sona erdiği için pekiştirmede çenelik veya monoblok düşünülmemiştir. Ancak hastanın tedavi sonrasındaki takibinde geç dönem mandibular büyüme ortaya çıkarsa geceleri monoblok kullanımı düşünülmektedir. 


\section{SONUÇ}

Orta dereceli mandibular protrüzyona bağlı iskeletsel Sınıf III malokluzyona sahip erişkin bir hastanın tedavisi, zigomatik buttress bölgesine yerleştirilen miniplaklardan Sınıf III elastiklerin kullanımı ile üst keser protrüzyonu olmaksızın mandibular dentisyonun en-masse distalizasyonu ile kısa sürede başarılı bir şekilde yapılmıştır.

\section{KAYNAKLAR}

1. Janson G, De Souza JE, Barros SE, Andrade P, Nakamura AY. Orthodontic Treatment Alternative to a Class III Subdivision Malocclusion. J Appl Oral Sci 2009;17:354-63.

2. Çelikoğlu M, Kiki A, Oktay H. İskeletsel Sınıf III Malokluzyonun Erken Dönem Tedavisi (Vaka Raporu). Atatürk Üniv Diş Hek Fak Derg 2009;19:192-7.

3. Guyer EC, Ellis EE, McNamara A, Behrents RG. Components of Class Iii Malocclusion in Juveniles and Adolescents. Angle Orthod 1986;56:7-30.

4. Williams S, Andersen CE. The Morphology of the Potential Class Iii Skeletal Pattern in the Growing Child. Am J Orthod 1986;89:302-11.

5. Ngan P, Yiu C, Hu A, Hagg U, Wei S H, Gunel E. Cephalometric and Occlusal Changes Following Maxillary Expansion and Protraction. Eur J Orthod 1998;20:237-54.

6. Vaughn GA, Mason B, Moon HB, Turley PK. The Effects of Maxillary Protraction Therapy with or without Rapid Palatal Expansion: A Prospective, Randomized Clinical Trial. Am J Orthod Dentofacial Orthop 2005;128:299-309.

7. Troy BA, Shanker S, Fields HW, Vig K, Johnston W. Comparison of Incisor Inclination in Patients with Class III Malocclusion Treated with Orthognathic Surgery or Orthodontic Camouflage. Am J Orthod Dentofacial Orthop 2009;135;146:46-7.

8. Ishikawa $H$, Nakamura $S$, Iwasaki $H$, Kitazawa $S$, Tsukada $\mathrm{H}$, Chu S. Dentoalveolar Compensation in Negative Overjet Cases. Angle Orthod 2000;70:145-8.

9. Lin J, Gu Y. Preliminary Investigation of Nonsurgical Treatment of Severe Skeletal Class III Malocclusion in the Permanent Dentition. Angle Orthod 2003;73:401-10.
10. Schoenwetter R. Nonsurgical Class III Orthodontic Treatment. Angle Orthod 1977;47:147-55.

11. Sperry TP, Speidel TM, Isaacson RJ, Worms FW. The Role of Dental Compensations in the Orthodontic Treatment of Mandibular Prognathism Angle Orthod 1977;47:293-9.

12. Jing $Y$, Han $X$, Guo $Y$, Li J, Bai D. Nonsurgical Correction of a Class III Malocclusion in an Adult by Miniscrew-Assisted Mandibular Dentition Distalization. Am J Orthod Dentofacial Orthop 2013;143:877-87.

13. Cao L, Zhang K, Bai D, Jing $Y$, Tian $Y$, Guo $Y$. Effect of Maxillary Incisor Labiolingual Inclination and Anteroposterior Position on Smiling Profile Esthetics. Angle Orthod 2011;81:121-9.

14. He S, Gao J, Wamalwa P, Wang Y, Zou S, Chen S. Camouflage Treatment of Skeletal Class III Malocclusion with Multiloop Edgewise Arch Wire and Modified Class III Elastics by Maxillary MiniImplant Anchorage. Angle Orthod 2013; 83:63040.

15. Proffit WR. Contemporary orthodontics. 4 ed St Louis; CV Mosby: 1992. p. 686-718.

16. Ellis E, McNamara JA. Components of Adult Class III Malocclusion. J Oral Maxillofac Surg 1984; 42:295-305.

17. Sugawara Y, Kuroda S, Tamamura N, and TakanoYamamoto T. Adult Patient with Mandibular Protrusion and Unstable Occlusion Treated with Titanium Screw Anchorage. Am J Orthod Dentofacial Orthop 2008;133:102-11.

18. Carano A, Velo S, Leone P, Siciliani G. Clinical Applications of the Miniscrew Anchorage System. J Clin Orthod 2005;39:9-24.

19. Chung KR, Kim SH, Kang YG, Nelson G. Orthodontic Miniplate with Tube as an Efficient Tool for Borderline Cases. Am J Orthod Dentofacial Orthop 2011;139:551-62.

\author{
Yazışma Adresi \\ Doç. Dr. Mevlüt ÇELİKOĞLU \\ Akdeniz Üniversitesi, \\ Diş Hekimliği Fakültesi \\ Ortodonti Ana Bilim Dalı, \\ Antalya, Türkiye. \\ Tel : +90242 2274400 \\ E-mail: mevlutcelikoglu@hotmail.com
}

